\title{
Open-Source Digital Technologies for Low-Cost Monitoring of Historical Constructions
}

\author{
Camilo Basto, Luca Pelà*, Rolando Chacón \\ Department of Civil and Environmental Engineering \\ Universitat Politècnica de Catalunya (UPC-BarcelonaTech), Barcelona, Spain
}

\begin{abstract}
This paper shows new possibilities of using novel, open-source, low-cost platforms for the structural health monitoring of heritage structures. The objective of the study is to present an assessment of increasingly available open-source digital modeling and fabrication technologies in order to identify the suitable counterparts of the typical components of a continuous static monitoring system for a historical construction. The results of the research include a simple case-study, which is presented with low-cost, open-source, calibrated components, as well as an assessment of different alternatives for deploying basic structural health monitoring arrangements. The results of the research show the great potential of these existing technologies that may help to promote a widespread and cost-efficient monitoring of the built cultural heritage. Such scenario may contribute to the onset of commonplace digital records of historical constructions in an open-source, versatile and reliable fashion.
\end{abstract}

Keywords: Structural Health Monitoring; Continuous Monitoring; Digital Fabrication; Digital Society; Do-It-Yourself; Low-Cost.

\section{Introduction}

The set of strategies aimed at identifying damage as well as the overall health conditions in structural systems is known as Structural Health Monitoring (SHM). SHM is an active field of research ranging from high precision aeronautical and automotive industries, the energy sector to, in a broader sense, civil engineering structures [1-5]. Roughly speaking, SHM systems include: i) sensors capable of acquiring a desired physical magnitude, ii) data-acquisition systems capable of storing and/or sending the obtained data and iii) a complex post-processing that involves the analysis of the obtained results. Structural systems of all kinds can be monitored and decisions are taken based upon real observations. Monitoring activities are usually costly since tailormade installations, heavily-wired deployments and sophisticated post-processing analysis are necessary for obtaining and understanding the health records of those structures.

SHM is a non-invasive survey process of paramount importance in the analysis of structures of the built cultural heritage. As a matter of fact, it represents an essential part of the modern integrated knowledge-based methodologies that establish a framework of

\footnotetext{
* corresponding author

e-mails: camilobasto@gmail.com (C. Basto), luca.pela@upc.edu (L. Pelà), rolando.chacon@upc.edu (R. Chacón).
} 
multi-disciplinary activities for the conservation and protection of heritage structures [68]. The design and implementation of a monitoring system in an historical construction is framed within a rigorous scientific process, including historical and geometrical survey of the structure, inspection on materials by in-situ and laboratory testing, mapping of existing damage and deformation and a subsequent structural analysis [910]. Combining and cross-correlating data from all these complementary activities, it is possible to detect relevant parameters to be controlled for defining the optimal deployment of the SHM system. SHM installations in historical constructions generally can gather environmental and behavioral data during either short- or long-term periods of time. Available systems for SHM of historical constructions are considerably expensive nowadays and are usually limited to highly valuable built heritage or eminently endangered zones [11-12].

On the other hand, open-source Digital Modeling and Fabrication (DMF) platforms are relatively novel tools that are bringing traditional industrial concepts related to Computer-Aided Design (CAD) and Computer-Aided Manufacturing (CAM) to the grasp of individuals. Do-It-Yourself (DIY) practitioners, enthusiasts and entrepreneurs are developing a fertile ecosystem of low-cost applications. The convergence of affordable additive and subtractive technologies (3D printing and laser-cutting), as well as the advent of open-source prototyping electronic platforms of hardware [13-15] and software [16-18], are unearthing endless possibilities for individuals in which creativity, entrepreneurship and innovation are fostered. The entire community is benefiting from these technologies in the age of open access information, in which ideas, methodologies and know-how is shared and cross-pollinated relentlessly [19-20].

This research presents a study on the possibility of building and testing a novel reproducible DIY system for SHM of historical structures. The paper is organized as follows. Section 2 presents a review of recent applications of DMF, as well as a brief overview of SHM for historical constructions. Section 3 analyses the simpler parts of a typical standard SHM deployment. The available open source DMF technologies are then explored to select the most suitable counterparts of the typical components of a continuous static monitoring system. Section 4 presents a case-study on a pilot case with active cracking problems on brickwork structural members, already known by the authors. This benchmark problem allowed the definition and calibration of a digital deployment intended to be applied to structures of the built cultural heritage. Finally, section 5 includes a critical discussion of the incomes of the research mainly based on advantages, limitations and challenges of the proposed methodology.

The results of the study are promising, since they show the real possibilities that opensource technologies may provide for acquiring useful digital data about the built cultural heritage, in a widespread but yet cost-efficient fashion.

\section{Review of background knowledge}

\subsection{Digital Modeling and Fabrication}

DMF is a rather broad term. It encompasses processes in which physical models can be recreated digitally by means of modeling tools and/or vice versa, by means of manufacturing tools. The back-and-forth nature of this physical-to-digital gap bridging includes hardware, software and manufacturing technologies that put together offer a 
vast array of possibilities to individuals. One may arguably state that DMF does not represent any novelty to the public, since it inherently includes the main cornerstones of any industrial process. However, two key aspects make DMF incredibly appealing for a vast array of collectives nowadays: i) the open-source philosophy in both hardware and software prototyping platforms and ii) the increasingly large community that share and cross-pollinate information through the Internet. Entire codes, circuitries, models, files and ideas are enthusiastically shared and implemented by entrepreneurs, DIYers, hobbyists, makers, students and in a broader sense, the whole community. This particular radical openness has fostered an exponential growth in fields such as environmental sensing [21-22], robotics [23-24], architecture [25-26], medicine and prosthetics [27-28], education [29-30] and a countless number of applications in manufacturing. Even though academic publishing relentlessly includes such enthusiasm, the vast majority of information is found in blogs, open-source video channels and content is spread out via social networks. Furthermore, there is a growing consensus that additive and subtractive technologies, such as 3D printing, may represent a major game-changer in the technological revolution. In fact, for some products, the manufacturing process may be totally tailor-made by the end-user and thus the need of industrial standard processes might vanish [31]. From the cultural heritage point of view, few academic researches involving DMF technologies have been recently published only for historical artefacts [32-34].

\subsection{Structural Health Monitoring of historical constructions}

SHM systems are usually composed by a set of sensors connected to an external data acquisition unit. Most modern solutions adopt wireless transmitters and receivers to overcome the limitations given by use of cables. Current systems usually adopt automatic sensors capable to monitor the structure continuously, i.e. providing real time measurements of the controlled variables. Continuous monitoring requires the adoption of huge storage capacity acquisition systems. In order to limit the amount of measures stored into the database, the systems can save the data at given time intervals. Another possibility is to set certain warning thresholds above which the system is activated (triggered monitoring). The stored raw data are eventually processed to extract relevant information (feature extraction) that is carefully analyzed by experts in order to draw valuable conclusions about current structural performance or serviceability. The results of SHM are essential to create and update reliable structural models which can be utilized to evaluate possible interventions or to understand better the origin of the detected anomalies.

In the last decades, the growing interest in efficient SHM systems for historical constructions has found the increasing support by the scientific community through advanced research [35-37]. Different types of monitoring strategies can be planned: one-time or periodical monitoring can be used to control the structural behaviour at a certain moment, before or after an intervention. Static monitoring is oriented to either long- or mid-term measurements of the gradual variation of environmental (e.g. temperature, humidity, wind, etc.) and structural variables (e.g. crack opening, displacement, deformation, etc.) by fixed sensors on the structure. Dynamic monitoring encompasses solutions for the repeated, episodic or continuous measurement of the dynamic response of the structure under forced or ambient vibrations [38]. Early 
warning monitoring is specifically oriented to the early detection of anomalous responses for decision-taking and timely actions [39].

SHM deployments aimed at monitoring the amplitude of the existing cracks are also available for heritage structures [40]. Digital crack meters are normally distributed over the most damaged parts of the investigated building, providing measurements either discretely or continuously. Digital crack meters should be always accompanied by temperature and humidity sensors to decouple the daily or seasonally cyclic effects of these environmental variables from the general behaviour trend. The analysis of the long term response of the crack, adequately depurated from periodical variations of temperature and humidity, can reveal if the damage is stable or if it is increasing and thus causing concern. Measurement of crack's width is recognized as a simple but efficient monitoring solution which is normally able to provide a quick and valuable insight into the current response of the building.

\section{Parts of a SHM deployment in Historical Constructions}

\subsection{Sensors}

The sources of information for a SHM system are the sensors. These analog components usually transform magnitudes associated with physical or chemical phenomena to voltages. Sensors associated with temperature, humidity, displacement, strain, air quality, noise, light, acceleration and pressure, are commercially available with a wide variety of prices and accuracy. Usually, for the depicted applications, the accuracy-price balance is affordable and provides satisfactory results. Sensors need to be powered and signals can be gathered and sent to the acquisition systems. Energy supply may include batteries, direct current, solar powered cells or others. Nowadays, these power-supply components can also be found in the market with a vast range of prices.

\subsection{Data Acquisition System (DAS)}

A digital controller or data acquisition system is then able to read the voltage variations and transform them into readable data (numbers). Only then it is possible to display, transfer, store, visualize or immediately treat the results. For a large system, a local network is usually assembled and all sensors send data to a centralized DAS. The devices usually gather the information in a central device or alternatively, intercommunicate. DASs include capabilities of capturing analog magnitudes with a certain frequency (usually it may be considerably fast, ranging from thousands of values per second to smaller frequencies). DAS used in high precision industries such as aeronautics are considerably powerful and may allocate up to 20000 simultaneous channels. Most modest systems (low-cost) are able to gather data from 5 to 20 sensors simultaneously with reasonable frequencies up to 500 values per second. 


\subsection{Data transmission and storage}

SHM systems must include the ability of storing and/or delivering information. These instruments may communicate with an on-site computer through USB cables or wireless protocols such as Bluetooth (cheap, short-range), xBee (private network with higher ranges), local $\mathrm{WiFi}$ or more remotely, via $3 \mathrm{G}$ mobile protocols. The used computer runs a data acquisition program in order to read the results and store them (usually in Comma, Separated Values CSV files). The information may be stored both in the sensors in an SD card and in the used computer. It is also possible to retrieve the information remotely either by internet accessing or by using a synchronizing program that copies the result files to the user's PC in real time. Generally, data-transmission and storage are performed by using specialized commercial software. Nowadays, opensource software is also available for the same needs in a low-cost fashion.

\subsection{Analysis, Alerts, signals, understanding}

Managing the SHM system can be a time consuming task, if it is poorly designed. A system of alerts for well-being of the structure and the monitoring system may be crucial to avoid both constant attention over long-term measurements and excessive storage of data. These alerts can come in the form of emails, SMS or simply as signals on the devices such as blinks or beeps. The interpretation of results is also a costly activity. A great amount of the post-processing work can be programmed into the system in order to provide easy to interpret results. It is possible to achieve higher control and reduce time consumption by controlling the exported file formats, plotting some of the desired graphs or cross-relating different measurements. Figure 1 shows the layout of a typical SHM deployment for a real structure.

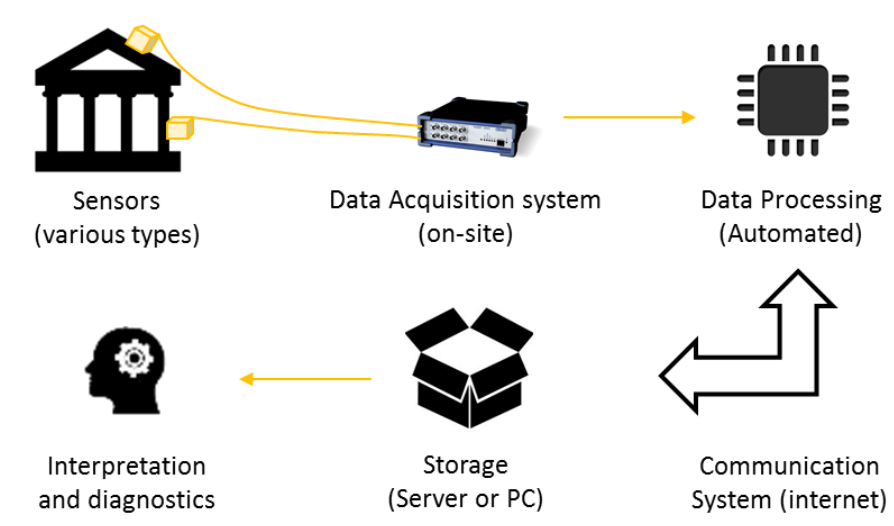

Figure 1 Different potential parts of SHM deployments in a real structure: sensors, data acquisition system, transmission and analysis.

\subsection{Advanced real-time analysis}

Readable data (numbers obtained from analog sensors) may be used directly for interpretation by analysts in the form of plots or graphs. There are, also, new possibilities related to the real-time usage of data for their public visualization in more pictorial ways. It is highly imaginable how numbers associated with temperature, light, 
noise or humidity within a historic site may be transformed in real time mapping of 3D models that may be, for instance, web located and publicly available. On the other hand, advanced visualizations of complex structural analysis may also be inferred by real-time data as shown in [41]. In both types of scenarios, conservators of historical constructions may account for affordable (both technically and economically) digital tools that may upgrade the cultural presence of historical constructions in the digital society. As in public spaces [42], open visualization of historical constructions is prone to ethical debate and scientific research in the years to come.

\section{Case-Study. SHM of an existing structure with low-cost and open- source technologies}

\subsection{Description}

A SHM deployment was assembled for the sake of studying low-cost and open-source alternatives available in the market for a crack monitoring system of an existing structure. This system was used to monitor a building inside the university facilities in Barcelona (School of Civil Engineering, UPC-BarcelonaTech). The building currently presents some visible active cracking problems on brickwork partitions and façades, already known by the authors. This simple benchmark problem with known behaviour was selected on purpose as a suitable pilot case-study to investigate and calibrate the newly implemented digital deployment. More in detail, the object of study was an approximately $2 \mathrm{~mm}$ wide crack found over the internal face of a nonstructural perimeter wall. Figure 2 shows the location of the SHM deployment. The system was performed in order to measure: i) crack width, ii) internal temperature, iii) external temperature and iv) internal relative humidity. Such magnitudes are those normally recorded during the static monitoring of existing cracks in historical structures, as already mentioned in Section 2.2. Open-source Arduino boards [13] were used as DAS and open-source software (Processing [16]) was used for the implementation of codes related to gathering information. More detailed explanations, codes and technical aspects of the study can be found in [43].

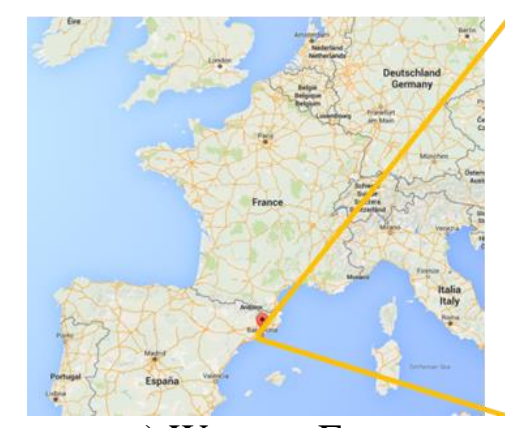

a) Western Europe

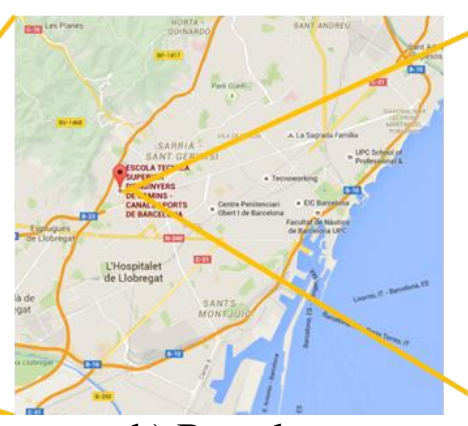

b) Barcelona

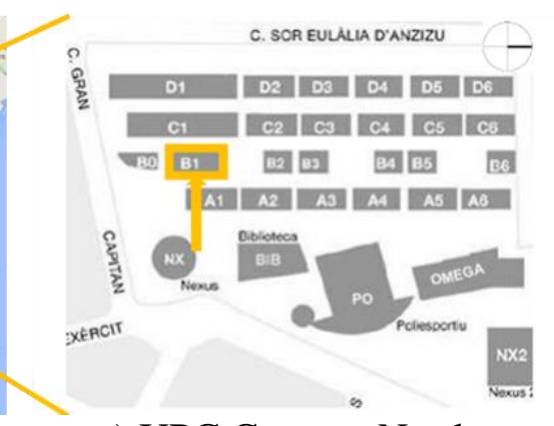

c) UPC Campus Nord

Figure 2 Location of the SHM deployment.

For the sake of studying several low-cost, open-source alternatives, three types of energy supply (ES), measurements and data management (DM) were studied. Figure 3 displays the corresponding ES and DM system for each measurement. 


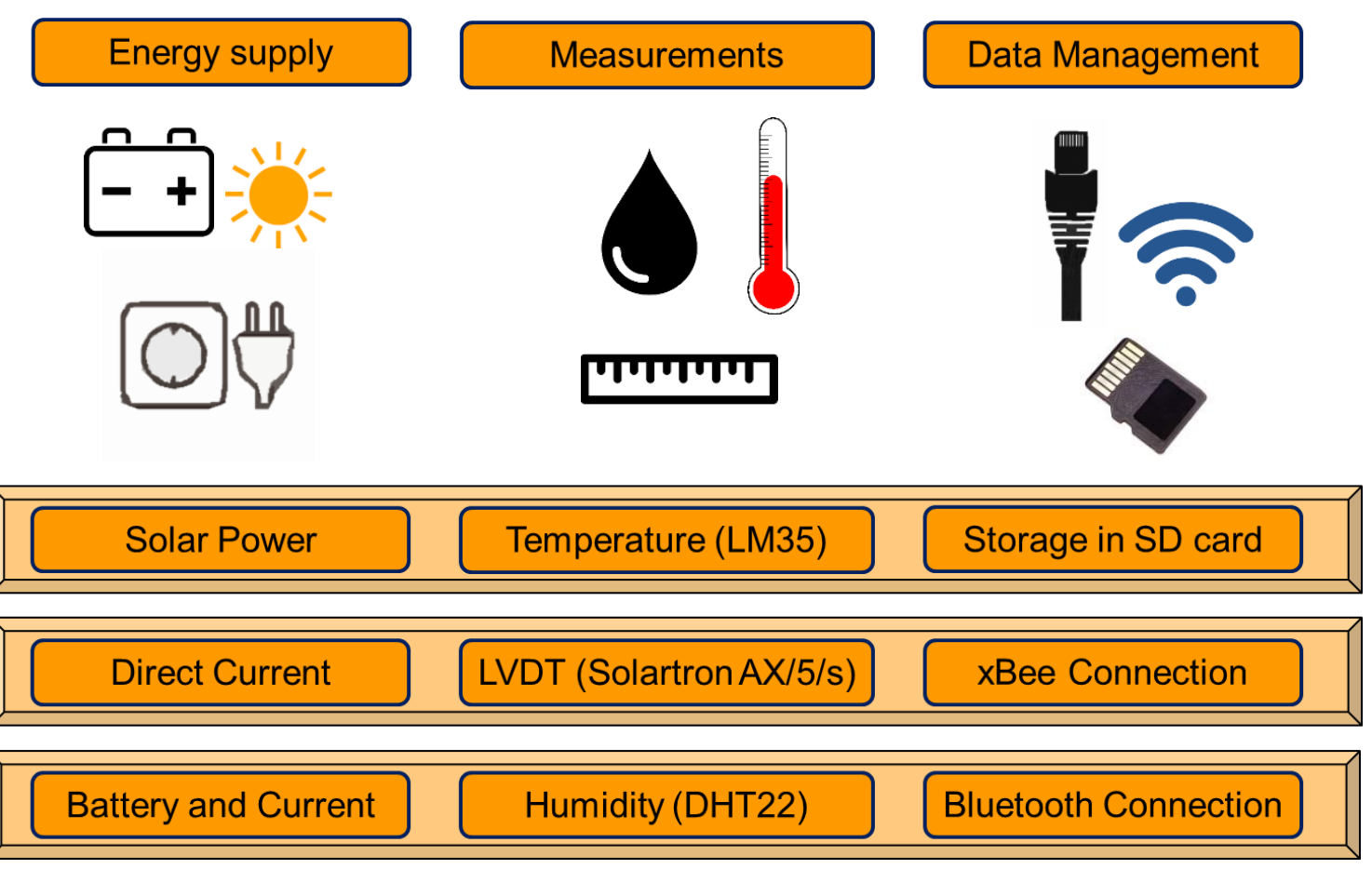

Figure 3 Set of alternatives adopted in the low-cost system for energy supply, measurement and data management.

The desired information was obtained using i) an LVDT over the crack (Solartron AX/5/S LVDT, accuracy $\pm 5 \mu \mathrm{m}$ ) controlled by a low-cost DAS (Arduino board). Both components were powered by an ATX power supply and wirelessly connected to an onsite PC via xBee technologies; ii) a humidity and temperature sensor inside the room in which the wall is located. The DAS was an Arduino board, powered by a laptop adapter and connected to the same on-site PC via Bluetooth; iii) a temperature sensor in a balcony controlled by an Arduino board and storing the information into a microSD card. The sensor and the board were powered by a low-cost solar power system (panel and battery). The description of the principal components employed in the implemented devices is reported in Table 1. 
Table 1 Technical features of the components used in the low-cost system.

\begin{tabular}{|c|c|c|}
\hline 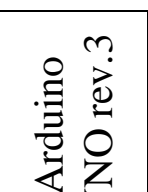 & 10: & $\begin{array}{l}\text { Previously programmed prototyping } \\
\text { board that digitally controls the device. }\end{array}$ \\
\hline 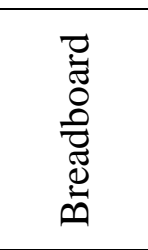 & 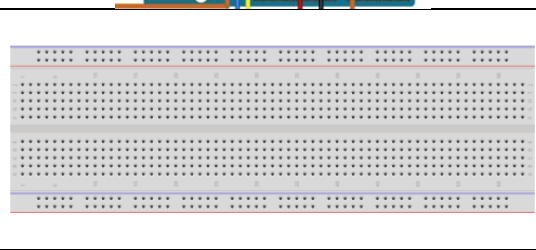 & $\begin{array}{l}\text { Prototyping board used for connection } \\
\text { of different elements. Power pin lines } \\
\text { are connected longitudinally and } \\
\text { general pins are connected transversally } \\
\text { in groups of } 5 .\end{array}$ \\
\hline 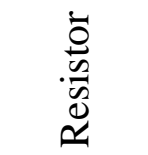 & $-\pi t=1$ & $\begin{array}{l}\text { Electrical components. In our case, used } \\
\text { mostly to control voltages. }\end{array}$ \\
\hline$\frac{\mathscr{8}}{8}$ & & $\begin{array}{c}\text { Allows current only in a single } \\
\text { direction. Because LVDT returns } \\
\text { positive or negative responses, it is } \\
\text { necessary to prevent inversion in the } \\
\text { system. }\end{array}$ \\
\hline 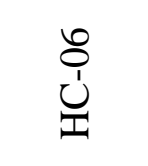 & 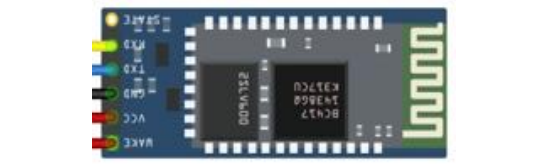 & $\begin{array}{l}\text { Bluetooth MODEM. Name and code } \\
\text { customized for controlled access. }\end{array}$ \\
\hline 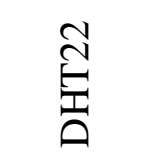 & 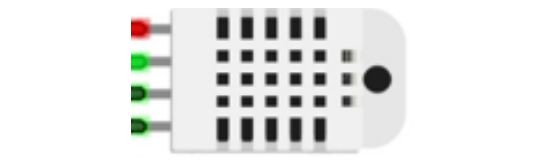 & $\begin{array}{l}\text { Humidity and Temperature sensor. } \\
\text { Accuracy: } \pm 2.5 \% \mathrm{RH} \text { and } \pm 0.5^{\circ} \mathrm{C}\end{array}$ \\
\hline 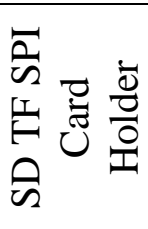 & 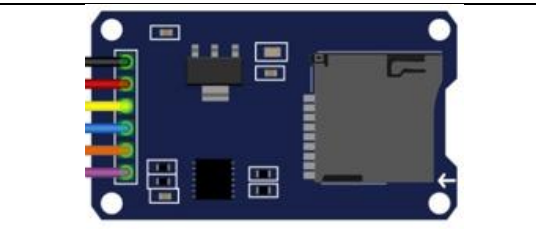 & $\begin{array}{l}\text { Connects a Micro-SD card. The model } \\
\text { used can connect to cards up to } 32 \mathrm{~Gb} \text {. } \\
\text { The Arduino board can create or edit } \\
\text { files and directories in it. }\end{array}$ \\
\hline $\begin{array}{l}\frac{y}{0} \\
0 \\
u \\
0 \\
\underline{v}\end{array}$ & : & $\begin{array}{l}\text { Provides a clock to the device, making } \\
\text { possible to register a date directly in the } \\
\text { device. It is fueled by a rechargeable } \\
\text { battery within the module. }\end{array}$ \\
\hline$\sum_{=}^{\infty}$ & se & Temperature sensor. Accuracy: $\pm 0.75^{\circ} \mathrm{C}$ \\
\hline 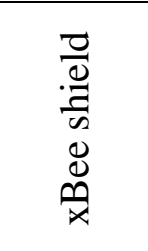 & 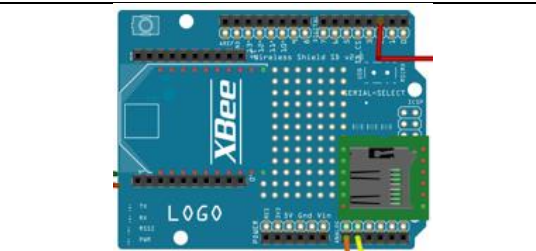 & $\begin{array}{c}\text { Module for connection with xBee } \\
\text { communication technology. It is placed } \\
\text { over the Arduino Uno Board. } \\
\text { Additionally it provides a slot for } \\
\text { micro-SD }\end{array}$ \\
\hline
\end{tabular}




\begin{tabular}{|c|c|}
\hline & \\
\hline &
\end{tabular}

Figure 4 displays the circuitry associated with each DAS. Figure 5 shows the built digital systems in their uncovered format. It is worth pointing out that these represent open-source prototyping platforms that could eventually be integrated in more professional, tailor-made boards for systematic applications and measurements.

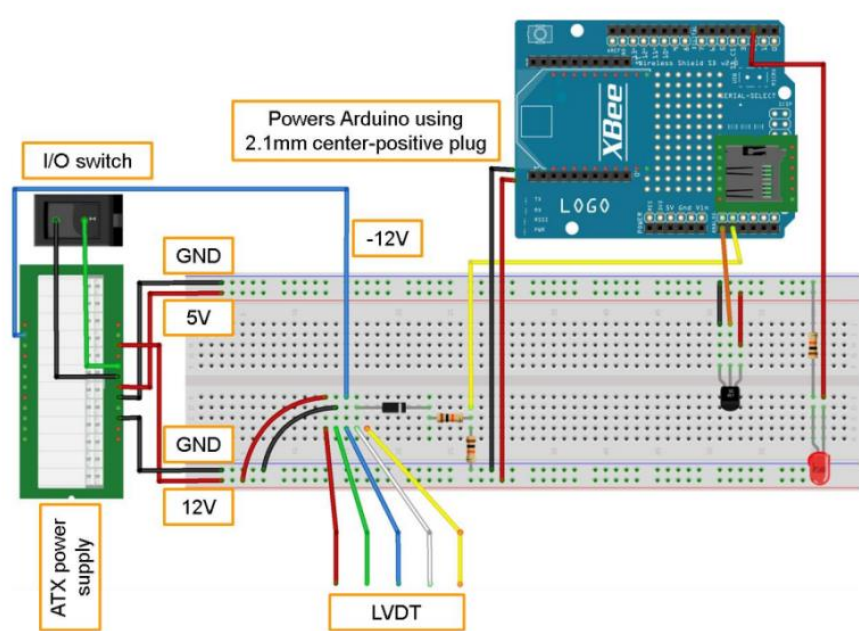

(a)

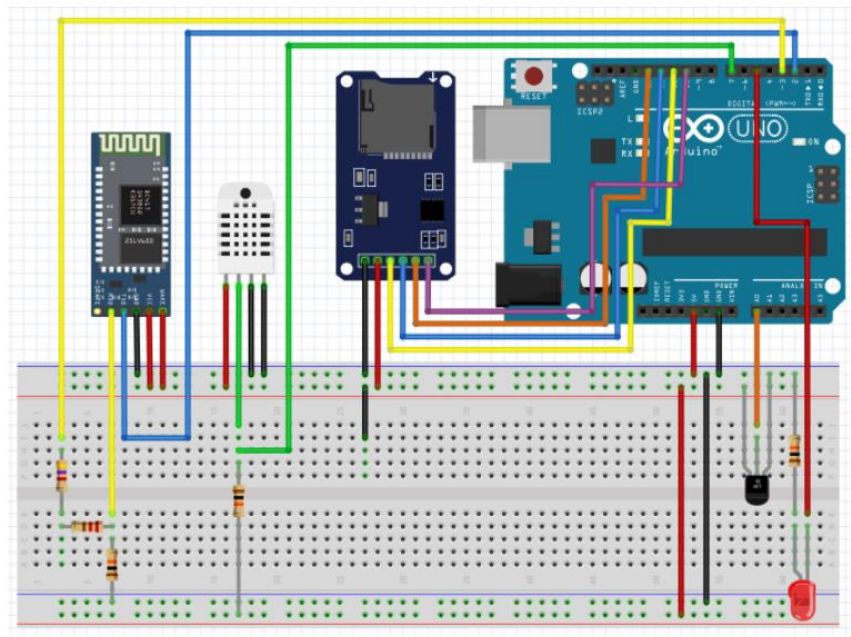

(b) 


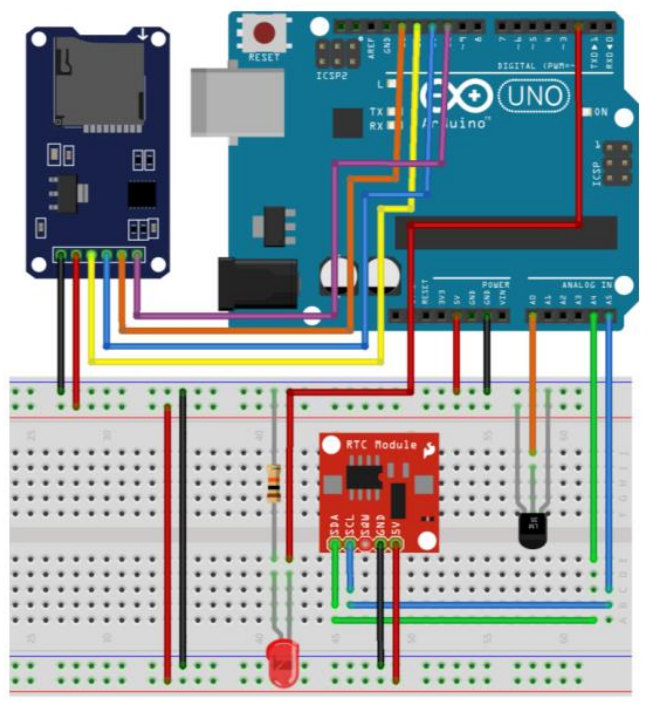

(c)

Figure 4 Circuitry and connections of sensors and data acquisition system in the implemented low-cost prototyping platforms to measure a) crack width, b) internal humidity and temperature, c) external temperature.

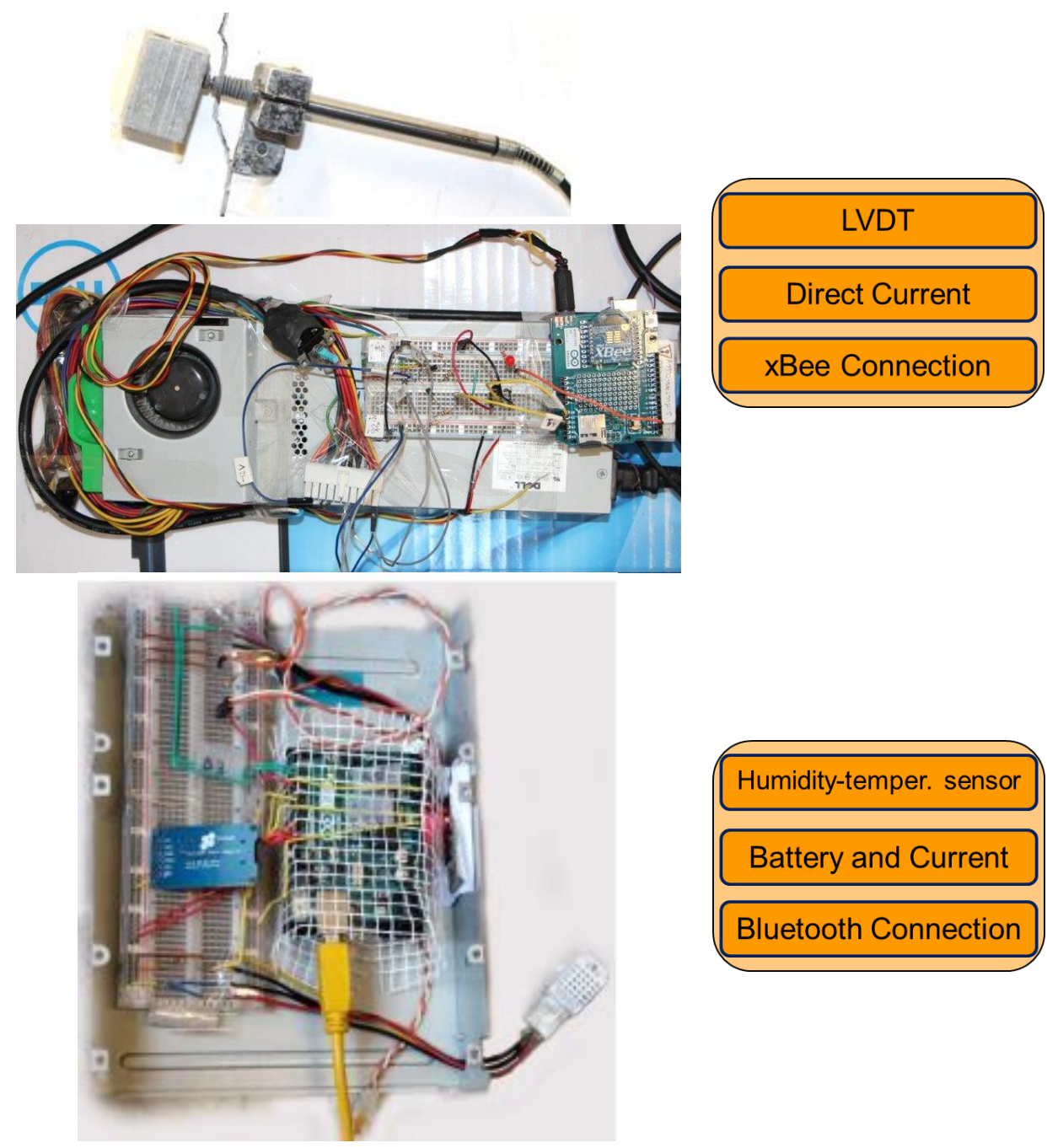

(a)

(b) 

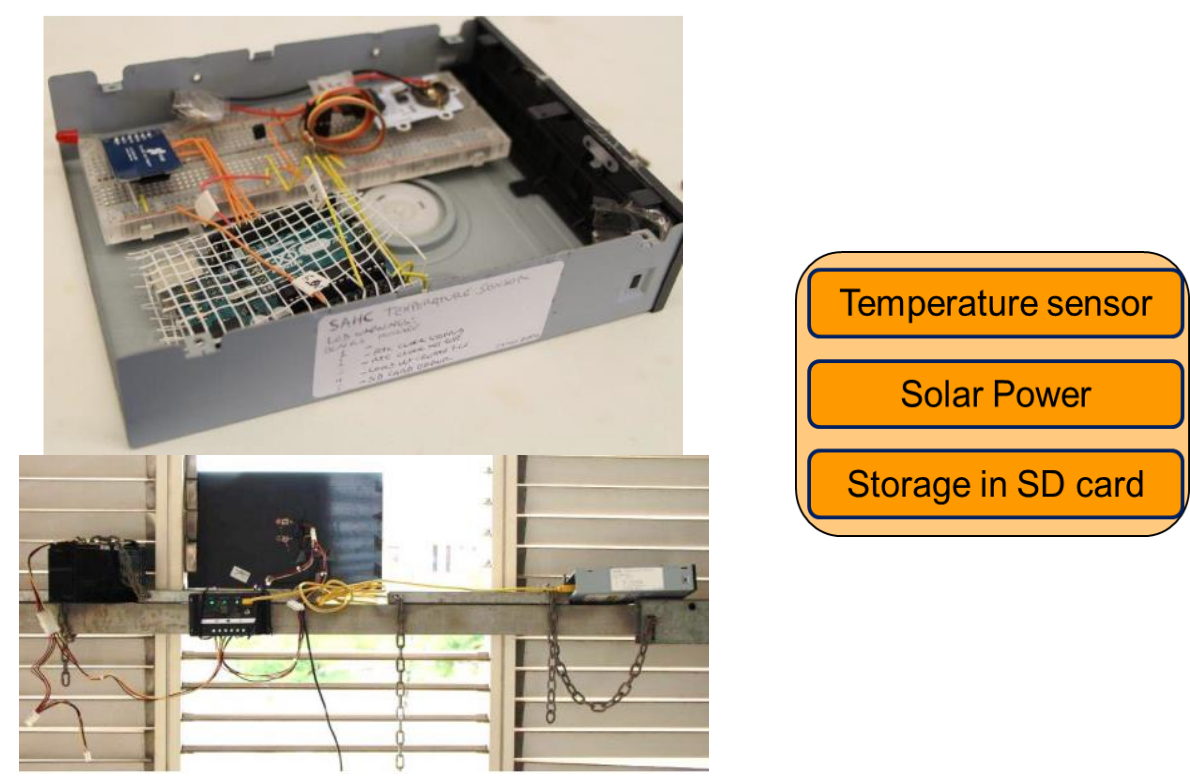

(c)

Figure 5 Uncovered format of the low-cost prototyping platforms to measure a) crack width, b) internal humidity and temperature, c) external temperature.

The data acquisition algorithm was implemented into the open-source software Processing [16] using Java language. The program recorded the acquired readings and displayed it by drawing points for each one. The flowcharts followed by the data acquisition programs for the three platforms are shown in Figure 6. All related codes are available open-source in [41].

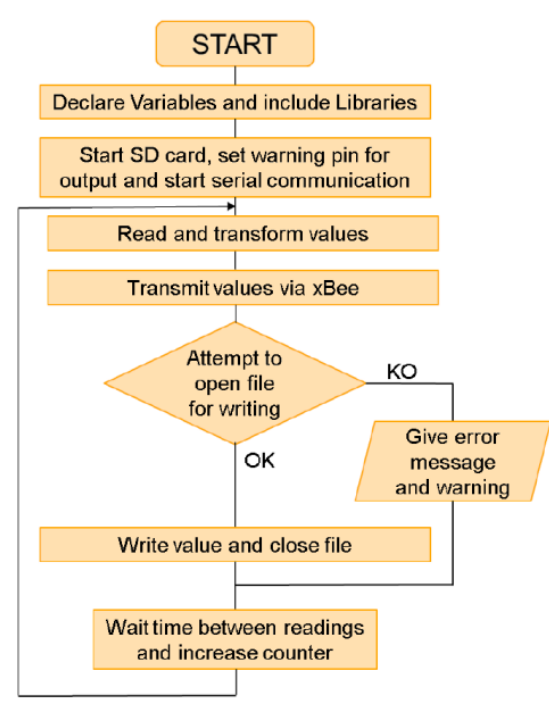

(a)

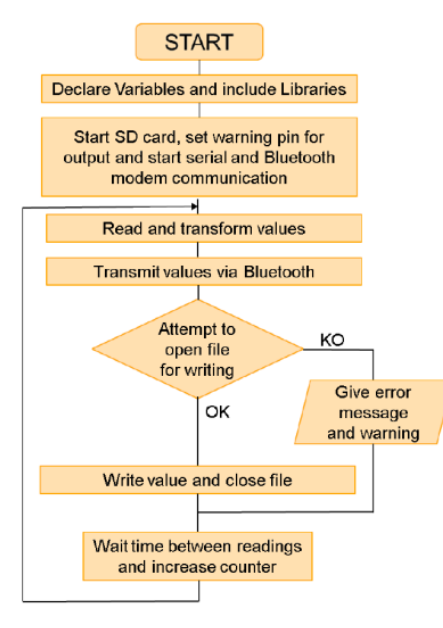

(b)

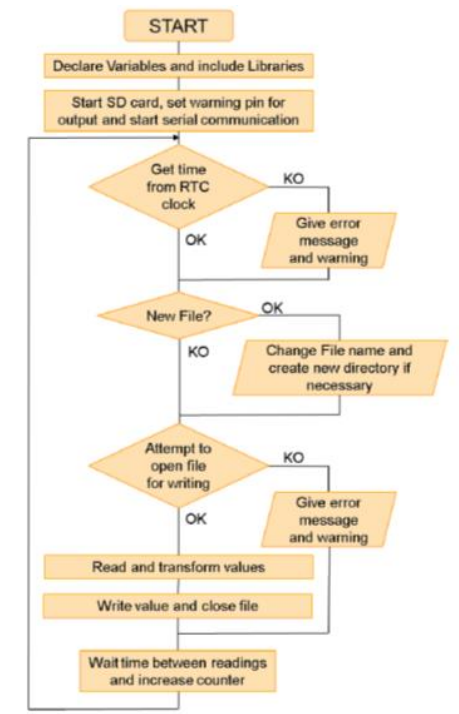

(c)

Figure 6 Flowcharts of data acquisition algorithms implemented into Processing [16] for a) crack width, b) internal humidity and temperature, c) external temperature. 


\subsection{Results}

Temperature (both indoors and outdoors), humidity (indoors) and crack width were monitored during a three week period in the month of June (summertime in Barcelona). Figure 7 displays indoors temperature and humidity variations. Figure 8 shows the results and the correlation found between outdoors temperature and the opening/closing of the monitored crack.

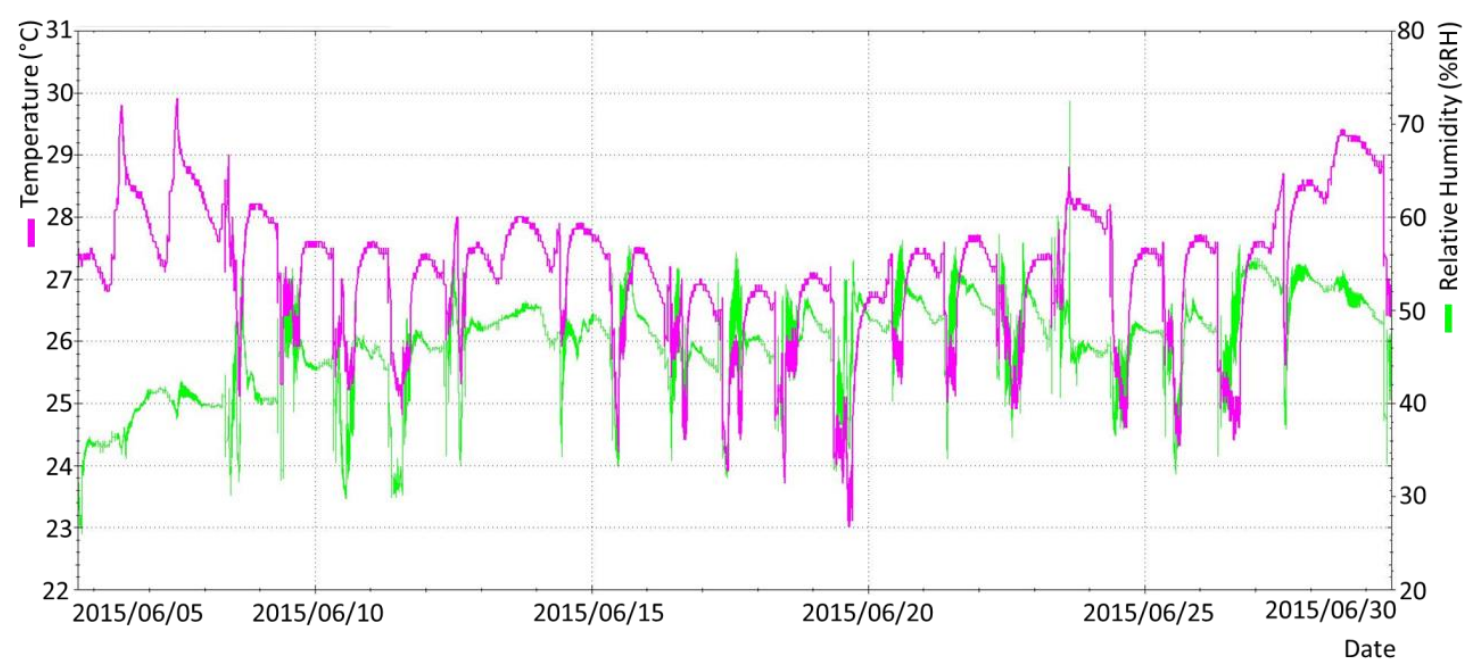

Figure 7 Values from DHT22 sensor (indoor temperature and humidity).

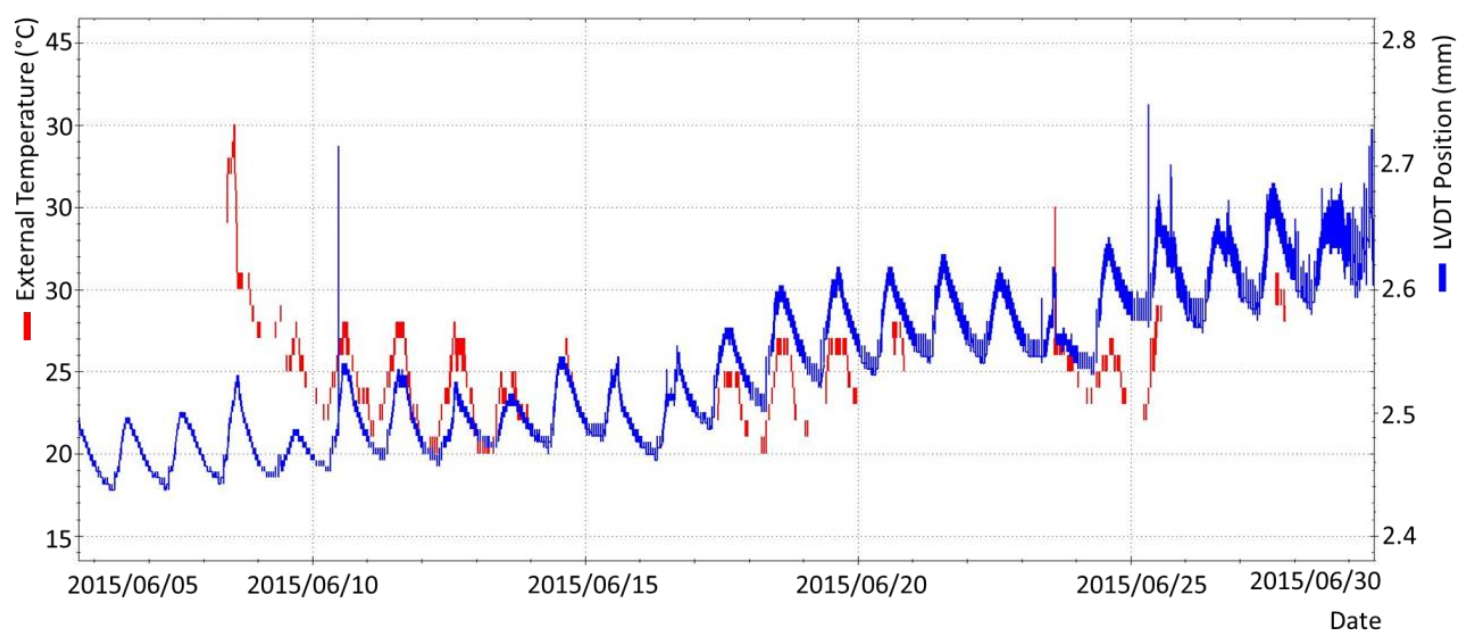

Figure 8 Values from LM35 sensor and LVDT (outdoor temperature and crack opening).

It is worth mentioning that the room was air-conditioned and accessed frequently by users of the building. Fluctuations of values during daytime and nighttime are observed as well as for the cases in which the central air-conditioning system was turned on/off (Figure 7). The outdoors temperature was recorded with a LM35 sensor powered by solar sources. A typical day/night cycle was observed. 
The plots concerning the crack opening as well as the outdoors temperature vs. time are displayed in Figure 8. The external temperature records were not as continuous as the LVDT ones, since the solar powered system had some power cuts due to positioning problems. However, all the other systems worked properly and it was possible to testify the movements of the internal crack and to relate them to the temperature and humidity. Noticeable parallelism between variables shows the correlation (at least visually) between crack opening and environmental magnitudes. This conclusion extracted from data may help in the decision-making process related to interventions associated with this particular crack.

\subsection{Cost-Time analysis}

The total investment into the production of the instruments was approximately $750 €$ and 183 hours of man-work. In order to better understand these values, two key aspects are worth pointing out: i) the LVDT made up to $60 \%$ of the monetary costs; ii) most of the man-hours were related to learning costs. It is estimated that repetition of the process would consume about $10 \%$ of this time but most importantly, a raise of awareness and education related to these particular technologies may contribute to their mainstream usage. As a consequence, these costs as well as the technical efforts would experience a considerable reduction.

Compared with products already available in the market, it was evident that there is an economical advantage only if these learning costs were not considered. It is also evident that there is a greater economic advantage the more complex the instrument is. The addition of features such as wireless connection, higher memory or coupling of several sensors is a simple process in the case of using prototyping platforms and has little extra costs.

\section{Discussion of results. Advantages, limitations and challenges}

The DFM platform presented in the previous section has shown his potential for SHM. Its application to a simple pilot case study has provided preliminary promising results. The study has addressed the development of a low-cost continuous static crack monitoring system including recording of environmental parameters (humidity, temperature). On the whole the deployment performed well and did not require any major debugging. Being the items mostly prototypes, the pins inside the instruments sometimes got loose, but this drawback could be easily overcome in next applications by using specifically-designed printed circuit boards. The battery responded as expected when powering the devices, even though direct current would be more advisable to maintain the instruments continuously on. Some positioning problems did not provide perfect stability to the solar system, but a better impermeable and polyvalent support, perhaps manufactured by 3D printing, could allow its better exposure. All the data storing alternatives that were explored worked correctly and other possibilities have also proven to be viable, such as remotely storing information via LAN using either Ethernet or Wi-Fi. Other data formats and different programs for post-processing are also object of interest. 
The preliminary good results indicate possible paths of improvement, as well as the possibility to extend the methodology to other types of monitoring systems adapted to very different problems and constraints.

The advantages of low-cost, open-source SHM deployments in historical constructions are primarily related to providing the opportunity to a vast array of sites, to start gathering digital info associated with environmental and behavioral variables. This first generation of data-acquisition may generate a boost of information useful for i) understanding the historical construction behavior, ii) understanding SHM by more conservators and citizens, iii) generating high quantities of digital data (a versatile format in the age of open access information) that could boost dissemination of knowledge associated with the cultural heritage, iv) generating real-time visualizations of results (contours, maps, web-based sites) that may allow further cultural exploitation of the monitored sites.

Currently, the limitations associated with SHM deployments are related with know-how and expertise. The SHM systems should be in any case carefully designed by specialists in order to assess its features, effectiveness and adequacy to the objectives of the study. Prices of electronic components are declining but the capacity (transmission, storage, acquisition) of components is soaring. Affordable SHM deployments are at the grasp of conservators for an unprecedented amount of sites. Education and dissemination of knowledge is still a limitation in many areas. However, a possible raise of awareness and education related to these particular technologies may help contribute to their mainstream usage. This scenario could reduce considerably the learning requirements, making the DFM platforms more accessible and thus promoting the knowledge sharing.

The main challenges of the studied novel techniques are associated to massive implementation of SHM in historical sites and also to robustness of the deployments. To do that, the offered option should constitute an appealing and feasible alternative to those commonly adopted by people involved in the conservation of the built cultural heritage. In current practice, whether a standard continuous monitoring system is not possible due to technical or economic constraints, monitoring is often achieved by the periodical or repeated application of inspection techniques, like for example discrete visual inspection with cracks' width measurements. As a result, low-cost deployments may provide, compared to the available approaches, not only substantial advantages in terms of cost and time efficiency but also high reliability. For this reason, careful costbenefit analysis should be done in the long term, including also control operation, calibration and maintenance costs of the novel SHM systems. As for the robustness of open-source and low-cost technology in SHM, it is worth mentioning that this drawback will be mitigated with time as systems are expected to become increasingly more sophisticated.

The ecosystem of new trends such as Smart Cities and the Internet of Things will boost in the years to come with the associated decline in prices and increment in data-quality. The development of more powerful or less expensive instruments will be increasingly possible. Awareness, education and implementation will empower conservators. In a near future, the singular point at which historical constructions provide reliable, digital data of their own behaviors may be feasible. 
Taking into considerations the aforementioned advantages, limitations and challenges, the following future lines of research may be envisaged at the end of the present study:

- the study of the possibilities related to real-time open visualization of results for further cultural exploitation of the monitored sites;

- the analysis of other types of available sensors compatible with open-source technologies for static monitoring, such as laser, infrared or ultrasonic distance meters in order to increase versatility and quality of data;

- the deployment of sensor networks in real heritage structures in order to study robustness and synchronicity of such low-cost arrangements;

- the development of low-cost systems for the dynamic monitoring of historical structures. Long-term and high frequency low-cost monitoring systems are still in their infancy and thus more research effort is required. An ongoing educational project by the authors, dealing with measurements of structural vibrations on reduced-scale models with open-source technologies, is currently providing some preliminary encouraging results.

\section{Conclusions}

The maintenance and safeguard of the built cultural heritage is one of the greatest challenges faced by conservators nowadays. The conservation often implies the application of retrofitting and rehabilitation actions that must be based upon rigorous experimental analyses performed by interdisciplinary teams. For the sake of deploying adequate solutions, SHM arrangements are usually needed. These installations in historical constructions are often costly due to their tailor-made nature as well as their long-term implementation and subsequent complex post-processing.

DMF technologies have evolved and developed to the point in which individuals may build tools and systems which, among other things, include low-cost and robust SHM deployments. The development of such systems combined with a raise of awareness of their advantages by conservators, could lead to the beginning of a new era of digitally recorded life of these constructions. This paper has shown that i) academic research related to SHM and DMF is growing and ii) costs and complexity of robust SHM deployments are going to plummet in the years to come. Consequently, records associated to the structural response of the monitored architectural cultural heritage are also likely to remarkably grow. This general trend will probably lead to the massive digitalization of the behaviour of historical constructions in the near future. The advantages of having constantly monitored structures could provide a much quicker understanding of their life-cycles, lower risk, more timely intervention and optimization of maintenance costs. In addition, open-source initiatives sharing digital data on monitored historical structures might provide a higher understanding and dissemination of knowledge among specialists, students or other enthusiasts. In this way, social awareness of the importance our heritage would grow and administrators of historical constructions could benefit from such a new scenario (Figure 9). Open share data associated to historical constructions may also lead to a real-time open visualization of their performance (structural, environmental or the like) that may foster further cultural exploitation of the built cultural heritage.

With an increasing number of historical constructions being monitored, the need for more effective gathering, visualization and displaying of digital results will surge in the near future. If more and more historical structures of the built cultural heritage are 
monitored, a technical and creative cross-pollination of case-studies will generate a considerable improvement of SHM in its dependability, accuracy and lifetime. Crosspollinating knowledge from monitored case-studies is only possible if numerous historical structures are monitored. Open-source DMF technologies and DIY deployments will be continuously enhanced, used and afforded by many more people. Once the physical-to-digital gap will be bridged by more conservators and the means for gathering the information will be improved, the built cultural heritage will be a target for digitalisation at several levels.

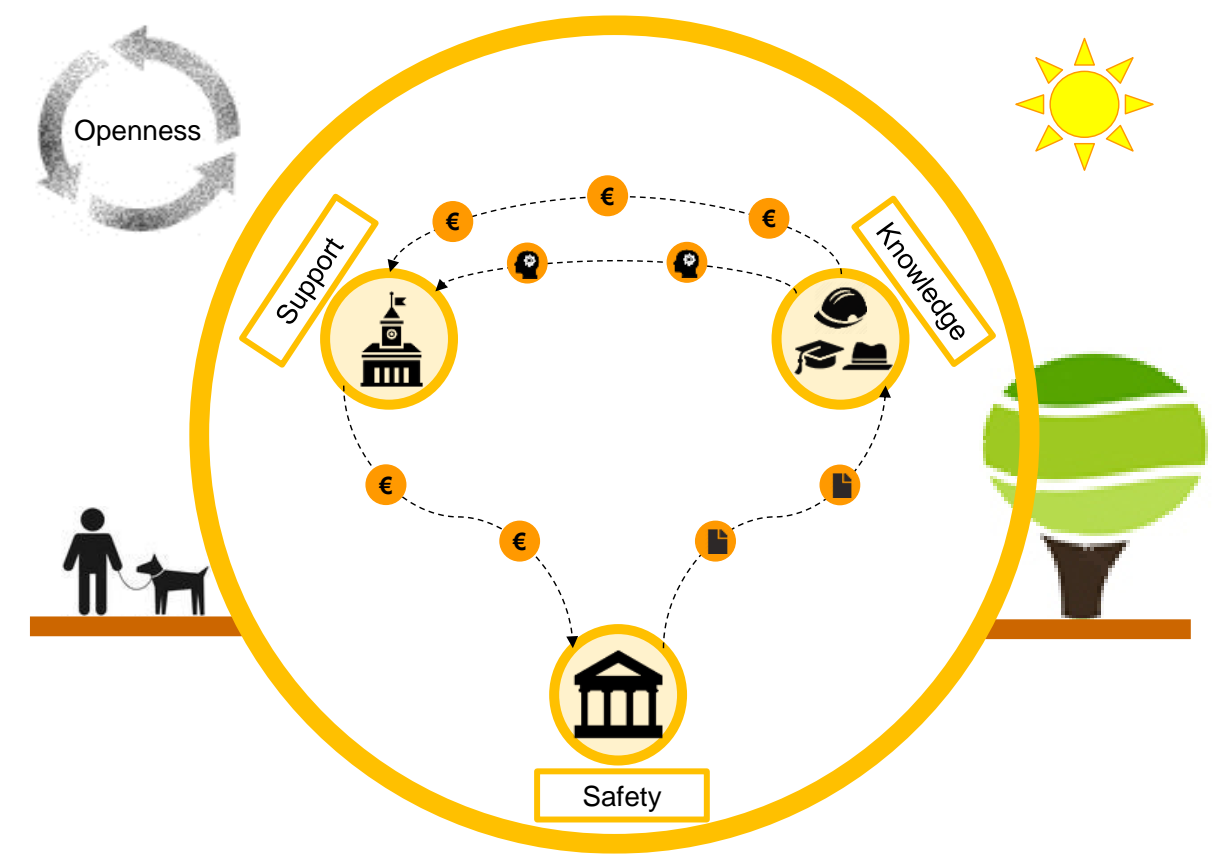

Figure 9 From openness of digital data to a safer built cultural heritage.

\section{Acknowledgments}

This research has received the financial support from the MINECO (Ministerio de Economia y Competitividad of the Spanish Government) through the MULTIMAS project (Multiscale techniques for the experimental and numerical analysis of the reliability of masonry structures, ref. num. BIA2015-63882-P).

\section{References}

[1] Kesavan A., John S., Herszberg I. Strain-based Structural Health Monitoring of Complex Composite Structures. Structural Health Monitoring. Vol. 7(3), pp 203-2011. 2008

[2] Sbarufatti C., Manes A., Giglio M. Application of sensor technologies for local and distributed structural health monitoring. Structural Control and Health Monitoring. Vol 21, pp 1057-1083. 2014

[3] Rumsey M., Farrar C. Structural health monitoring of wind turbines: method and application to a HAWT. Wind Energy. Vol. 14 (4), pp 603-623. 2014 
[4] Chacón R., Zorrilla R. Structural health monitoring in incrementally launched steel bridges: Patch loading phenomena modeling. Automation in Construction. Vol 58, pp 60-73. 2015

[5] Hu X., Wang B., Ji H. A Wireless Sensor Network-Based Structural Health Monitoring System for Highway Bridges. Computer-aided civil and infrastructure engineering. Vol 38 (3), pp: 193-209. 2013

[6] ICOMOS/ISCARSAH Committee (2005) Recommendations for the analysis, conservation and structural restoration of architectural heritage. http://www.icomos.org/en/. 2005

[7] ISO/FDIS 13822:2010 (E) Bases for design of structures — Assessment of existing structures. Annex I: Heritage Structures. 2010

[8] D9.2-NIKER. Development and calibration of local and global monitoring techniques during tests on elements, connections and buildings. Report, NIKER project - New Integrated Knowledge based approaches to the protection cultural heritage from Earthquake induced Risk, WP09 - Knowledge Based Assessment. 2012 http://niker.eu/

[9] Bosiljkov V, Uranjek M, Zarnic R, Bokan-Bosiljkov V. An integrated diagnostic approach for the assessment of historic masonry structures. Journal of Cultural Heritage 11, 239-249. 2010

[10] Roca P., Cervera M., Gariup G., Pelà L. Structural Analysis of Masonry Historical Constructions. Classical and Advanced Approaches. Archives of Computational Methods in Engineering, 17(3):299-325. 2010

[11] Lorenzoni F, Casarin F, Modena C, Caldon M, Islami K, da Porto F. Structural health monitoring of the Roman Arena of Verona, Italy. Journal of Civil Structural Health Monitoring, 3:227-246. 2013

[12] Russo S. On the monitoring of historic Anime Sante church damaged by earthquake in L'Aquila. Structural Control and Health Monitoring; 20:1226-1239. 2013

[13] Arduino. http://www.arduino.cc

[14] Raspberry Pi. http://www.raspberrypi.org

[15] Adafruit platform. http://www.adafruit.com

[16] Processing. http://processing.org

[17] Python. http://www.python.org

[18] MIT Appinventor. http://appinventor.mit.edu

[19] Pearce J. Open-Source Lab. How to Build Your Own Hardware and Reduce Research Costs. 1st Edition. Elsevier. USA-UK-The Netherlands. 2014

[20] Fox S. Third Wave Do-It-Yourself (DIY): Potential for prosumption, innovation, and entrepreneurship by local populations in regions without industrial manufacturing infrastructure. Technology in Society. Vol 39 (11). pp 11-30. 2014 
[21] Ferdoush S., Li X. Wireless Sensor Network System Design using Raspberry Pi and Arduino for Environmental Monitoring Applications. Procedia Computer Science. Vol 34. pp103-110. 2014

[22] Mesas-Carrascosa F., Verdú Santano D., Meroño J., Sánchez de la Orden M., García-Ferrer A. Open source hardware to monitor environmental parameters in precision agriculture. Biosystems Engineering. Vol. 137, pp. 73-83. 2015

[23] Bonarini A., Matteucci M., Migliavacca M., Rizzi D. R2P: An open source hardware and software modular approach to robot prototyping. Robotics and Autonomous Sytems. Vol. 62(7), pp. 1073-1084. 2014

[24] Aburaia M., Markl E., Stuja K. New Concept for Design and Control of 4 Axis Robot Using the Additive Manufacturing Technology. Procedia Engineering. Vol.100, pp. 1364-1369. 2015

[25] Vujovic V., Maksimovic M. Raspberry Pi as a sensor web node for home automation. Computers \& Electrical Engineering. Vol. 44, pp. 153-171. 2015

[26] Kensek K.M. Integration of environmental sensors with BIM: case studies using Arduino, Dynamo, and the REVIT API. Informes de la Construcción. Vol 66 (536), e044. 2014.

[27] Zandparsa R. Digital Imaging and Fabrication. Dental Clinics of North America. Vol. 58(1), pp. 135-158. 2014

[28] Teikari P., Najjar R., Malkki H., Knoblauch K., Dumortier D., Gronfier C., Gronfier C., Cooper H. An inexpensive Arduino-based LED stimulator system for vision research. Journal of Neuroscience Methods. Vol. 211(2), pp. 227-236. 2012

[29] Koenka I., Sáiz J., Hauser P., Instrumentino: An open-source modular Python framework for controlling Arduino based experimental instruments. Computer Physics Communications. Vol 185(1). pp 2724-2729. 2014

[30] Eguchi A. RoboCupJunior for promoting STEM education, 21st century skills, and technological advancement through robotics competition. Robotics and Autonomous Systems. Available online August 2015. RoboCupJunior for promoting STEM education, 21st century skills, and technological advancement through robotics competition

[31] Rayna T., Striukova L. From rapid prototyping to home fabrication: How 3D printing is changing business model innovation. Technological Forecasting and Social Change. Available online septembre 2015. doi:10.1016/j.techfore.2015.07.023

[32] Arbace L., Sonnino E., Callieri M., Dellepiane M., Fabbri M., Iaccarino A., Scopigno R. Innovative uses of $3 \mathrm{D}$ digital technologies to assist the restoration of a fragmented terracotta statue. Journal of Cultural Heritage. Vol.14(4)., pp.332-345. 2013

[33] Zhang X., Blaas J., Botha C., Reischig P., Bravin A., Dik J. Process for the 3D virtual reconstruction of a microcultural heritage artifact obtained by synchrotron radiation CT technology using open source and free software. Journal of Cultural Heritage. Vol.13(2)., pp. 221-225. 2012

[34] McKnight L., Adams J., Chamberlain A., Atherton-Woolham S., Bibb R. Application of clinical imaging and 3D printing to the identification of anomalies in an ancient Egyptian animal mummy. Journal of Archeological Science: Reports. Vol.3, pp. 328-332. 2015 
[35] Elyamani A. Integrated monitoring and structural analysis strategies for the study of large historical construction. Application to Mallorca cathedral. PhD Dissertation, Technical University of Catalonia, Barcelona, Spain. 2015

[36] Lorenzoni F. Integrated methodologies based on Structural health monitoring for the protection of cutural heritage buildings. PhD Dissertation, University of Trento, Italy. 2013

[37] Lorenzoni F, Casarin F, Caldon M, Islami K, Modena C. Uncertainty quantification in structural health monitoring: Applications on cultural heritage buildings. Mechanical Systems and Signal Processing 66-67, 268-281. 2016

[38] Ramos LF, Marques L, Lourenço PB, DeRoeck G, Campos-Costa A, Roque J. Monitoring historical masonry structures with operational modal analysis: Two case studies. Mechanical Systems and Signal Processing 24, 1291-1305. 2010

[39] Binda L, Modena C, Casarin F, Lorenzoni F, Cantini L, Munda S. Emergency actions and investigations on cultural heritage after the L'Aquila earthquake: the case of the Spanish Fortress. Bulletin of Earthquake Engineering 9:105-138. 2011

[40] Ottoni F, Blasi C. Results of a 60-Year Monitoring System for Santa Maria del Fiore Dome in Florence. International Journal of Architectural Heritage, 9:1, 7-24. 2015

[41] Huang J., Ong S., Nee A. Real-time finite element structural analysis in augmented reality. Advances in Engineering Software. 87, 43-556. 2015

[42] Valkanova N., Jorda S., Vande Moere A. Public visualization displays of citizen data: Design, impact and implications. International Journal of Human-Computer Studies. 81, 4-16. 2015

[43] Basto C. Study on possibilities for low-cost monitoring of historical structures. SAHC Master Dissertation (Advanced Master in Structural Analysis of Monuments and Historical Constructions), Technical University of Catalonia, Barcelona, Spain. 2015 (available on line at: http://www.msc-sahc.org/) 